\title{
Utility of total lymphocyte count as a surrogate marker for CD4 counts in HIV-1 infected children in Kenya
}

Nyawira Githinji ${ }^{1}$, Elizabeth Maleche-Obimbo ${ }^{1}$, Moses Nderitu², Dalton C Wamalwa ${ }^{{ }^{*}}$ and Dorothy Mbori-Ngacha ${ }^{1}$

\begin{abstract}
Background: In resource-limited settings, such as Kenya, access to CD4 testing is limited. Therefore, evaluation of less expensive laboratory diagnostics is urgently needed to diagnose immuno-suppression in children.

Objectives: To evaluate utility of total lymphocyte count (TLC) as surrogate marker for CD4 count in HIV-infected children.

Methods: This was a hospital based retrospective study conducted in three HIV clinics in Kisumu and Nairobi in Kenya. TLC, CD4 count and CD4 percent data were abstracted from hospital records of 487 antiretroviral-naïve HIVinfected children aged 1 month - 12 years.

Results: TLC and CD4 count were positively correlated $(r=0.66, p<0.001)$ with highest correlation seen in children with severe immuno-suppression $(r=0.72, p<0.001)$ and children $>59$ months of age $(r=0.68, p<$ 0.001). Children were considered to have severe immuno-suppression if they met the following WHO set CD4 count thresholds: age below 12 months (CD4 counts < 1500 cells $/ \mathrm{mm}^{3}$ ), age 12-35 months (CD4 count < 750 cells/mm3), age 36-59 months (CD4 count $<350$ cells $/ \mathrm{mm}^{3}$, and age above 59 months (CD4 count $<200$ cells/ $\mathrm{mm}^{3}$ ). WHO recommended TLC threshold values for severe immuno-suppression of 4000, 3000, 2500 and 2000 cells $/ \mathrm{mm}^{3}$ for age categories $<12,12-35,36-59$ and $>59$ months had low sensitivity of 25\%, 23\%, 33\% and 62\% respectively in predicting severe immuno-suppression using CD4 count as gold standard. Raising TLC thresholds to $7000,6000,4500$ and 3000 cells $/ \mathrm{mm}^{3}$ for each of the stated age categories increased sensitivity to $71 \%, 64 \%, 56 \%$ and $86 \%$, with positive predictive values of $85 \%, 61 \%, 37 \%, 68 \%$ respectively but reduced specificity to $73 \%, 62 \%$, $54 \%$ and $68 \%$ with negative predictive values of $54 \%, 65 \%, 71 \%$ and $87 \%$ respectively.

Conclusion: TLC is positively correlated with absolute CD4 count in children but current WHO age-specific thresholds had low sensitivity to identify severely immunosuppressed Kenyan children. Sensitivity and therefore utility of TLC to identify immuno-suppressed children may be improved by raising the TLC cut off levels across the various age categories.
\end{abstract}

Keywords: Total Lymphocyte Count, TLC, CD4, HIV, Children, surrogate marker

\section{Background}

There are an estimated 200,000 HIV-1 infected children in Kenya the majority of whom acquired the infection perinatally $[1,2]$. Without treatment, the mortality of these children in Kenya and similar resource-poor settings approaches $50 \%$ by the age of 2 years, with most

\footnotetext{
* Correspondence: dalton@africaonline.co.ke

'Department of Pediatrics and Child Health, University of Nairobi, Nairobi, Kenya

Full list of author information is available at the end of the article
}

deaths attributable to infectious illnesses and failure to thrive [3-6]. Recent scale-up of highly active antiretroviral therapy (HAART) has resulted in improved survival, however less than $30 \%$ of eligible children are currently receiving HAART [7-10]. Factors that undermine further expansion of pediatric HAART coverage in the Kenyan context include late diagnosis, lack of health personnel trained in antiretroviral therapy (ART) delivery and limited laboratory infrastructure for CD4 testing [2]. The critical role of CD4 cell count/percent in
Ciomed Central

() 2011 Githinji et al; licensee BioMed Central Ltd. This is an Open Access article distributed under the terms of the Creative Commons Attribution License (http://creativecommons.org/licenses/by/2.0), which permits unrestricted use, distribution, and reproduction in any medium, provided the original work is properly cited. 
predicting clinical progression of pediatric HIV-1 is well described [11-13]. The diagnostic work-up of HIV-1 infected children is considered incomplete without review of CD4 results despite the fact that this test is not routinely available in most rural Kenyan settings that bear the greatest burden of pediatric HIV. There are an estimated 100 machines for CD4 testing (FACSCount ${ }^{\circledR}$ or FACSCalibre ${ }^{\circledR}$ ) in Kenya of which only 35 are located in public health facilities which serve the majority of HIV-1 infected children, while the remainder are found in large private hospitals and clinics, largely in urban settings. The cost of performing a CD4 count in Kenya is estimated at US\$12 which is at least 4 times higher than that of a total lymphocyte count. In 2006 the World Health Organization (WHO) recommended the use of total lymphocyte count (TLC) as a guide for initiating ART in children with WHO clinical stage 2 who are aged 8 years and below in settings where CD4 counts are not available [14]. In adult studies, correlation between the TLC and CD4 counts ranged from 0.64 to 0.78 , and appeared to be stronger for patients with advanced disease [15-18].

The sensitivity of the recommended TLC levels of $<1200$ cells $/ \mathrm{mm}^{3}$ for predicting CD4 counts below 200 cells $/ \mathrm{mm}^{3}$ in adult studies has been however found to vary widely from $38 \%$ to $75 \%$ while the positive predictive value has ranged between $64 \%$ to $88 \%[16-19]$. A sensitivity of $75 \%$ means that the recommended TLC cut off will only detect three quarters of those with true CD4-defined immuno-suppression and miss one quarter. On the other hand a positive predictive value of $88 \%$ implies that among children found to have immunosuppression by a given TLC cut-off, $88 \%$ will meet the CD4 criteria for immuno-suppression [20]. Given the aggressive nature of pediatric HIV, any diagnostic test employed must have very high sensitivity since missing a diagnosis of severe immuno-suppression would result in increased mortality [3]. On the other hand low positive predictive value would lead to misclassification with children who otherwise have good immunity being categorized as severely immunosuppressed and inadvertently started on HAART, thus increasing costs and risk of toxicity. A meta-analysis by Dunn on a large group of children in US and Europe found TLC $<2500$ cells $/ \mathrm{mm}^{3}$ or CD4 percent $<20 \%$ to be associated with high mortality [21].

As part of the Kenya's efforts to meet the recently published PEPAR II goals, an estimated 100,000 children need to be newly initiated on HAART before 2013 [22]. In order to realize this goal, new treatment centers need to be established and some of these may not immediately have access to routine CD4 testing. Hence it is pertinent" to validate the use of TLC as surrogate for CD4 counts in local settings. This is especially critical since most existing data are largely drawn from the US and Western Europe and may not be directly applicable to local settings. Furthermore there is need for region specific validation of CD4 and TLC counts changes both "Pre-HAART" and on HAART. Our study was designed to determine the diagnostic utility of TLC as a surrogate for CD4 counts and correlation between TLC and CD4 counts in Kenya children attending HIV clinics in three sites.

\section{Methods}

This was a retrospective hospital based cross-sectional survey, carried out at three hospitals in Kenya; Kenyatta National Referral Hospital (KNH) in Nairobi, Mbagathi District Hospital (MDH) in Nairobi, and New Nyanza Provincial General Hospital (NNPGH) in Kisumu, western Kenya. All HIV infected children aged between one month and twelve years on follow-up in the comprehensive HIV care clinics (CCC) at the three hospitals who had medical records on CD4 count and total lymphocyte at enrollment into care prior to initiation of ART were eligible for inclusion in the study.

The medical records of children receiving care between January 2004 and July 2006 were reviewed. "Evidence of HIV status was sought, specifically, by documentation of a positive HIV antibody test for children above 18 months, or positive HIV PCR test result for children below 18 months. For eligible children, data on age, sex, WHO clinical stage, absolute CD4 count and TLC data prior to ART initiation was abstracted from medical records. Any child missing any of these data was excluded. Children were consecutively enrolled from each site until the desired sample size was achieved. We excluded children under the age of one month due to uncertainty of HIV diagnosis in this group.

Approval to conduct the study was sought from the Ethical Review Committee of $\mathrm{KNH}$ which is the teaching hospital of the University of Nairobi, as well as from the administration of the Mbagathi and New Nyanza Hospitals. Confidentiality was maintained for all abstracted patient records which were identified only by number stored in a secure computer.

\section{Statistical Methods}

Data was analyzed using STATA version 9.2. Correlation between all pairs of TLC, CD4 cell count, and TLC and $\mathrm{CD} 4 \%$ (all as continuous variables) were determined using Spearman's correlation coefficient. Children were then categorized into four age groups <12, 12-35, 36-59 and $>59$ months. We also categorized children by presence or absence of severe immuno-suppression based on WHO 2006 age specific immunologic categorizations as follows: age $<12$ months CD $4<$ versus $\geq 1500$ cells/ 
$\mathrm{mm}^{3}, 12-35$ months CD $4<$ versus $\geq 750$ cells $/ \mathrm{mm}^{3}, 36$ 59 months CD $4<$ versus $\geq 350$ cells $/ \mathrm{mm}^{3}$ and $>59$ months CD $4<$ versus $\geq 200$ cells $/ \mathrm{mm}^{3}$. Similarly severe immune-suppression by CD4 percentage was defined as CD $4 \%<25 \%,<20 \%,<15 \%$ and $<15 \%$ for ages $<12$ months, 12-35, 36-59, and $>59$ months respectively [14].

TLC was categorized using WHO age-specific TLC thresholds defining presence or absence of immuno-suppression stratified by the same age categories as follows: $<$ versus $\geq 4000$ cells $/ \mathrm{mm}^{3}, 3000$ cells $/ \mathrm{mm}^{3}, 2500$ and 2000 cells $/ \mathrm{mm}^{3}$ respectively [14]. The sensitivity, specificity, positive predictive value (PPV) negative predictive values (NPV) of the WHO TLC cut-offs in predicting severe immune-suppression as defined by WHO CD4 thresholds were determined. Data was analyzed to determine the optimal TLC cut-offs that provide highest sensitivity and specificity for predicting severe immunesuppression.

\section{Results}

We identified 487 ART naive HIV infected children who had complete records, including 125 children from NNPGH, 186 from MDH and 176 from KNH. Two hundred and twenty three (46\%) were female and the median age was 36 months (IQR 18-68, Table 1).

\section{Clinical Parameters and CD4 Profile}

Prior to starting ART 95 (20\%) children had WHO clinical stage 1 or 2 disease, while $392(80 \%)$ had stage 3 or 4 disease (Table 1 ). The median CD4 count was 537 cells $/ \mathrm{mm}^{3}$ (IQR 216-992), median CD4 percentage $11.6 \%$ (IQR 5.7-19), and median TLC (TLC) was 4500 cells $/ \mathrm{mm}^{3}$ (IQR 2700-6655). The median CD4 count decreased with rising age, and was 1060, 777, 565 and 226 cells $/ \mathrm{mm}^{3}$ in children of age $<12,12-35,36-59$ and

Table 1 Descriptive Characteristics of Study Population (n = 487)

\begin{tabular}{ll}
\hline Characteristic & Frequency (\%) or Median (IQR) \\
\hline Hospital & \\
New Nyanza Provincial Hospital & $125(25.7)$ \\
Mbagathi District Hospital & $186(38.2)$ \\
Kenyatta National Hospital & $176(36.1)$ \\
\hline Female & $223(46)$ \\
\hline Age in months & $36(18-68)$ \\
\hline Age group & \\
$<12$ months & $82(17)$ \\
$12-35$ months & $129(26)$ \\
$36-59$ months & $118(24)$ \\
$>59$ months & $158(32)$ \\
\hline WHO Clinical Stage & \\
1 and 2 & $96(19.7)$ \\
3 and 4 & $390(80.2)$ \\
\hline
\end{tabular}

$>59$ months respectively. The corresponding median CD4\% for children in the four age categories in ascending order was $17.5 \%, 12.3 \%, 11.9 \%$, and $7.4 \%$. The median TLC was 6895, 6000, 4513 and 2577 cells $/ \mathrm{mm}^{3}$ among children of the four age groups (Table 2). We categorized children as either severely immunosuppressed or not based on age-specific thresholds of CD4 count, CD4\%, and TLC based on WHO 2006 classifications (Table 2).

\section{Correlation between CD4 Counts and Total Lymphocyte Counts}

Correlation between absolute CD4 counts and the TLC for the whole study population was 0.66 (Spearman correlation coefficient). In the individual sites correlation was as follows: KNH (0.76), MDH (0.55), and NNPGH (0.54). Correlation between CD4 counts and TLC was then explored among different age groups, and stratified by presence or absence of severe immuno-suppression. Correlation among children $<12$ months was 0.54 , for 12-35 months it was 0.44 , for $36-59$ months, 0.38 , and for $>59$ months correlation was 0.68 . The strongest correlation was seen in the oldest group of children $(>59$ months). Correlation between CD4 count and TLC among children who were severely immunosuppressed was 0.72 which was higher than their counterparts without severe immuno-suppression correlation 0.63. Overall correlation between TLC and CD4\% was weak ( $\mathrm{r}=$ 0.06).

\section{Diagnostic Utility of TLC to identify Severely Immuno- suppressed Children}

To test the utility of TLC as a surrogate marker for CD4 count, sensitivity, specificity, PPV and NPV of TLC was determined using WHO 2006 recommended cut off values for absolute CD4 count as the gold standard. Table 3 shows the proportion of children classified according to presence of severe immuno-suppression as defined by both CD4 count and TLC and stratified by age while table 4 shows the same with additional stratification by WHO clinical stage. The sensitivity of WHO recommended age-specific TLC thresholds to identify severely immune-suppressed children was low, ranging from 23 to $62 \%$ while specificity was high ranging from $83 \%$ to $100 \%$. PPV was high ranging from $68 \%$ to $100 \%$ while NPV ranged from $37 \%$ to $74 \%$ (Table 5).

\section{Raising Cut off Values of TLC to Improve Diagnostic Utility}

Since the recommended WHO TLC cut offs for identifying severe immuno-suppression in all age categories had low sensitivity, we explored whether raising the TLC cut offs would improve the sensitivity without unduly compromising the specificity. As an alternative 
Table 2 CD4 counts and Percent and Total Lymphocyte Count by Age Category

\begin{tabular}{|c|c|c|c|c|}
\hline $\begin{array}{l}\text { Age group in } \\
\text { months }\end{array}$ & $\begin{array}{l}\text { CD4 count (cells } / \mathrm{mm}^{3} \text { ) Median } \\
\text { (range) }\end{array}$ & $\begin{array}{l}\text { CD4 percentage Median } \\
\text { (range) }\end{array}$ & $\begin{array}{l}\text { TLC (cells } / \mathrm{mm}^{3} \text { ) Median } \\
\text { (range) }\end{array}$ & $\begin{array}{l}\text { No. of } \\
\text { children }\end{array}$ \\
\hline$<12$ & $1060(604-1590)$ & $17.5(10.5-23.6)$ & $6895(4875-8670))$ & 82 \\
\hline $12-35$ & 777 (400-1123) & $12.3(7.2-18)$ & $6000(3770-8035)$ & 129 \\
\hline $36-59$ & $565(250-880)$ & $11.9(5-8-21.9)$ & $4513(3289-5511)$ & 118 \\
\hline$>59$ & $226(35-430)$ & $7.4(1.6-14)$ & $2577(1675-4100)$ & 158 \\
\hline ALL & 537 (216-992) & $11.6((5.7-190)$ & $4500(2700-6655)$ & 487 \\
\hline
\end{tabular}

to receiver operating characteristic curve for simultaneously evaluating how sensitivity and specificity vary as the cutoff point is changed, we plotted sensitivity and specificity against various TLC cut off points. The plots for different age groups were used to determine optimal cut off points which are defined as the TLC value that yields the highest sensitivity while maintaining acceptable specificity (Figure 1). For age category $<12$ months, raising the TLC cut off from WHO 4000 cells $/ \mathrm{mm}^{3}$ to 7000 cells $/ \mathrm{mm}^{3}$ improved the sensitivity from $25 \%$ to $71 \%$, but decreased specificity from $100 \%$ to $73 \%$ (Table 4). Similarly for age group 12-35 months, raising the TLC cut off value from 3000 cells $/ \mathrm{mm}^{3}$ to 6000 cells/ $\mathrm{mm}^{3}$ improved the sensitivity from $23 \%$ to $65 \%$ accompanied by a decreased specificity from $98 \%$ to $62 \%$. For age category 36-59 months, raising the TLC cut off value from 2500 cells $/ \mathrm{mm}^{3}$ to 4500 cells $/ \mathrm{mm}^{3}$ would improve the sensitivity from $33 \%$ to approximately $60 \%$. For age category $>59$ months, raising the TLC cut off from 2000 cells $/ \mathrm{mm}^{3}$ to 3000 cells $/ \mathrm{mm}^{3}$ would improve the sensitivity from $62 \%$ to $86 \%$ but lead to a loss in specificity from $83 \%$ to $68 \%$. A mean value across age groups was computed for each variable at the current WHO TLC threshold, and at new proposed threshold. The mean sensitivity improved considerably from $36 \%$ to $71 \%$, mean specificity decreased from $93 \%$ to $64 \%$, mean PPV dropped from $84 \%$ to $63 \%$, mean NPV improved from $61 \%$ to $69 \%$ (Table 5).

\section{Discussion}

Several studies in adults and a few in children have suggested that TLC may be used as surrogates of CD4+ T cell count in HIV infected patients [17,18,22,23]. Our study was designed to evaluate the utility of TLC to identify immuno-suppression in HIV infected children from three pediatric HIV care centers in Kenya. In our study population, TLC was positively correlated with CD4 count (overall $r=0.66$ ), with stronger correlation among children with severely depressed CD4 counts. We found the WHO 2006 TLC thresholds defining immuno-suppression to have low sensitivity but high specificity for detecting severely depressed CD4 count in these Kenyan children, and sensitivity was lowest among young children under 5 years $(<34 \%)$. In contrast to the CD4 count, there was very poor correlation between TLC and CD4\% $(r=0.06)$ similar to weak correlation ( $\mathrm{r}$ $=0.01$ ) reported by Musoke in Ugandan children [24].

The WHO recommendations for use of TLC as surrogate marker for CD4 count for decision in initiating HAART in children is based upon the premise that TLC is easily available and easy to perform relative to the CD4 assays. As a good surrogate marker the TLC cut-off values should be highly sensitive in identifying children of low CD4 count requiring HAART. Stated differently, a good tool should not miss immuno-suppressed children who are at highest risk of mortality. In our study population, between 67 and $75 \%$ of the children aged below 5 years who require ART would have been missed by the WHO TLC thresholds used suggesting low utility in HIV program settings.

In order to improve the utility of TLC we explored raising the cut-off values to levels higher than those recommended by the WHO 2006 guidelines. We used the point of maximal sensitivity with least compromise in specificity as the new optimal TLC cutoff point. We thus selected increased TLC thresholds that would give optimized combination of good sensitivity, with acceptable specificity and PPV. This resulted in improved mean sensitivity of the TLC from $36 \%$ to $71 \%$ for detection of severe immuno-suppression in our population, while

Table 3 Proportion of Children Immuno-suppressed by Age Category

\begin{tabular}{lllll}
\hline $\begin{array}{l}\text { Age group in } \\
\text { months }\end{array}$ & $\begin{array}{l}\text { Severely depressed CD4 count } \\
\text { Frequency (\%) }\end{array}$ & $\begin{array}{l}\text { Severely depressed CD4 percentage } \\
\text { Frequency (\%) }\end{array}$ & $\begin{array}{l}\text { Depressed TLC } \\
\text { Frequency (\%) }\end{array}$ & $\begin{array}{l}\text { No. of } \\
\text { Children }\end{array}$ \\
\hline$<12$ & $56(68.3)$ & $62(48.1)$ & $13(15.9)$ & 82 \\
$12-35$ & $62(48.1)$ & $102(79.1)$ & $15(12.4)$ & 129 \\
$36-59$ & $39(33.3)$ & $75(63.6)$ & $19(16.1)$ & 118 \\
$>59$ & $69(43.7)$ & $127(80.4)$ & $58(36.7)$ & 158 \\
\hline ALL & $226(46.2)$ & $371(76.2)$ & $105(21.6)$ & 487 \\
\hline
\end{tabular}


Table 4 Proportion of Children Immuno-suppressed by Age Category stratified by WHO clinical stage.

\begin{tabular}{lllll}
\hline WHO Clinical Stage & Age group in months & Severely depressed CD4 count Frequency (\%) & Depressed TLC Frequency (\%) & No. of Children \\
\hline Stage 1-2 & $<12$ & $12(60)$ & $1(5)$ & 20 \\
& $12-35$ & $9 *(35)$ & $1(3.8)$ & 26 \\
& $36-59$ & $4(13)$ & $5(16.1)$ & 31 \\
& $>59$ & $5(26)$ & $7(36.8)$ & 19 \\
& All & $30(31)$ & $14(14.6)$ & 96 \\
\hline Stage 3-4 & $<12$ & $44(71)$ & $12(19.4)$ & 62 \\
& $12-35$ & $52(51)$ & $14(13.7)$ & 102 \\
& $36-59$ & $35(40)$ & $14(16.1)$ & 87 \\
& $>59$ & $64(46)$ & $51(36.7)$ & 139 \\
\hline ALL & All & $195(50)$ & $91(23.3)$ & 390 \\
\hline
\end{tabular}

*One child in this age category did not have WHO clinical stage excluded from this table

retaining acceptable specificity (mean 68\%) and PPV (mean 63\%). Examining the effect of raising TLC threshold more closely, in the age category $<12$ months, the proposed raised TLC threshold of 7000 cells $/ \mathrm{mm}^{3}$ yielded improved sensitivity of $71 \%$ (previously $25 \%$ ), meaning that new threshold would identify 7 of 10 immuno-suppressed children needing ART compared to 2 of 10 identified by the previous threshold of 4000 cells $/ \mathrm{mm}^{3}$. Given that HIV is uniformly fatal in the absence of interventions, improved sensitivities for the raised TLC threshold favors the use of TLC as a screening tool for severe immuno-suppression in settings where CD4 monitoring is not easily accessible.

On the other hand, further increasing TLC thresholds beyond the optimized levels we selected based on our cohort data would grossly decrease specificity and PPV for relatively little incremental gain in sensitivity. This would result in unacceptably high numbers of children who are actually not severely immune-depleted being misclassified and started on ART earlier than they require, exposing them unnecessarily to the problems associated with ART including adverse drug effects, development of antiretroviral drug resistance well as increasing the cost of running programs purchase of expensive medications.

Considering that the clinical staging of disease is also employed together with the immunological criteria in order to initiate HAART, in this study we recommend raising the TLC cut-offs from the current WHO recommended TLC cut-off values. Raising TLC cut off values to improve sensitivity and enable TLC to be used as a better screening tool has been previously proposed by adult studies in Uganda and Kenya $[17,18]$. A Ugandan study in adults found TLC values of 2100 cells $/ \mathrm{mm}^{3}$ to best predict CD $4<200$ cells $/ \mathrm{mm}^{3}$ (sensitivity $83 \%$, specificity $77 \%$, PPV $92 \%$, NPV 57\%) which was superior to a cut-off value of 1200 [19]. In Kenyan adults, raising the TLC cut off value from the recommended 1200 cells/mm3 to 1900 cells/mm3 resulted in improved diagnostic utility for predicting CD $4<200$ cells $/ \mathrm{mm}^{3}$ (sensitivity $81 \%$, specificity $90 \%$, PPV $90 \%$, NPV $80 \%$ ) [17]. The higher cut off value for TLC required to improve

Table 5 Sensitivity, Specificity, PPV and NPV of Current WHO TLC thresholds and Proposed new raised TLC thresholds to Identify Severely Immuno-suppressed Children

\begin{tabular}{|c|c|c|c|c|c|c|}
\hline Age group in months & Current WHO TLC threshold (cells $/ \mathrm{mm}^{3}$ ) & Sensitivity & Specificity & $\mathrm{PPV}^{\mathrm{a}}$ & $\mathrm{NPV}^{\mathrm{b}}$ & No. of children \\
\hline$<12$ & 4000 & 25 & 100 & 100 & 37 & 82 \\
\hline $12-35$ & 3000 & 23 & 98 & 93 & 58 & 129 \\
\hline $36-59$ & 2500 & 33 & 92 & 68 & 74 & 118 \\
\hline$>59$ & 2000 & 62 & 83 & 74 & 74 & 158 \\
\hline ALL & & $36^{c}$ & $93^{\mathrm{C}}$ & $84^{c}$ & $61^{c}$ & 487 \\
\hline Age group in months & Proposed Optimal TLC & Sensitivity & Specificity & PPV & NPV & No. of Children \\
\hline$<12$ & 7000 & 71 & 73 & 85 & 54 & 82 \\
\hline $12-35$ & 6000 & 65 & 62 & 61 & 65 & 129 \\
\hline $36-59$ & 4500 & 60 & 54 & 37 & 71 & 118 \\
\hline$>59$ & 3000 & 86 & 68 & 68 & 87 & 158 \\
\hline ALL & & 71 & 64 & 63 & 69 & 487 \\
\hline
\end{tabular}

${ }^{\mathrm{a} P P V}=$ positive predictive value ${ }^{\mathrm{b}} \mathrm{NPV}=$ negative predictive value ${ }^{\mathrm{c}}$ Mean value for the four age groups 

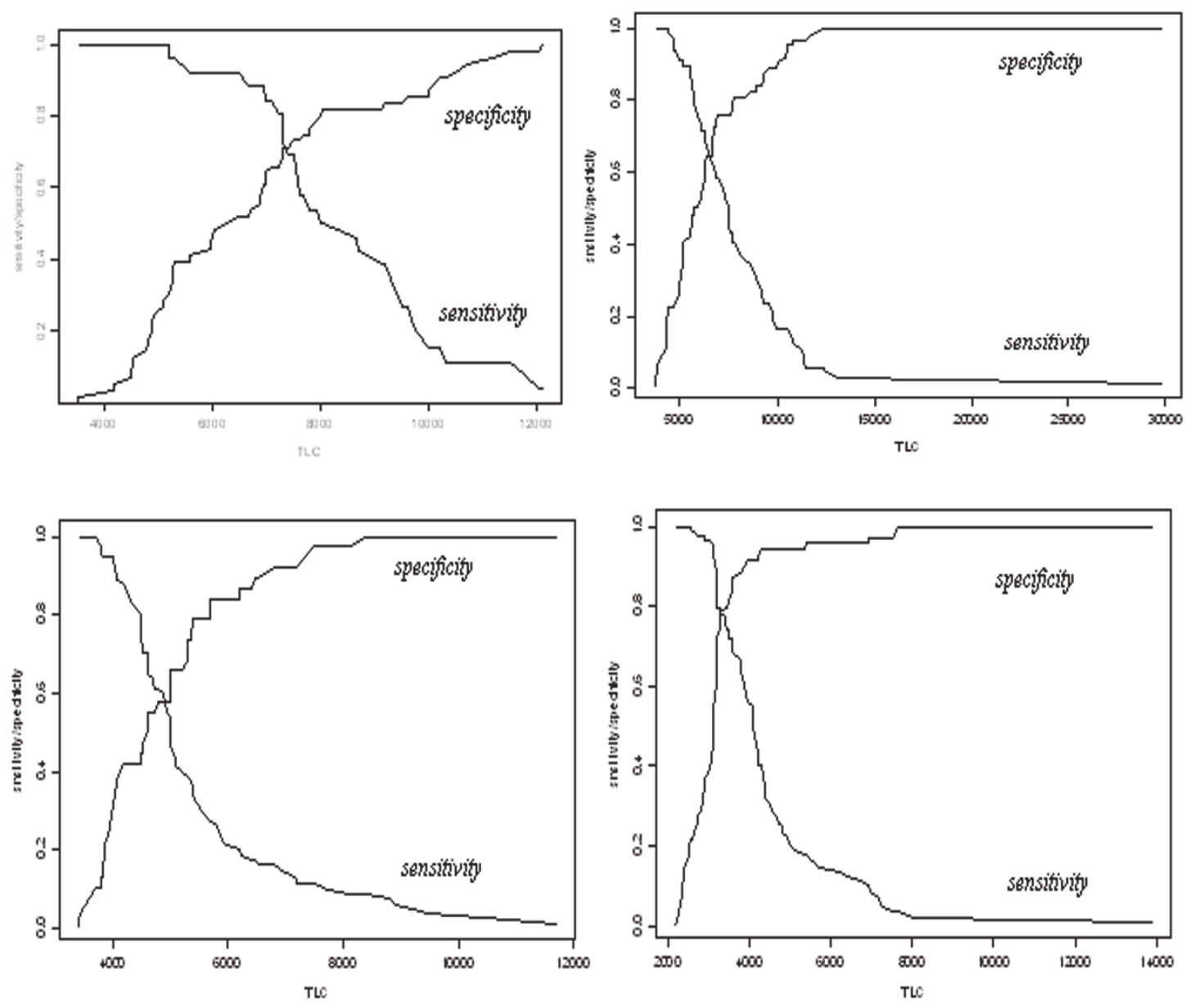

Figure 1 Optimal sensitivity and specificity for various TLC cut-offs by Age Group. Sensitivity and specificity of TLC to detect severe immune-suppression was plotted against various total lymphocyte count (cells/mm ${ }^{3}$ ) cut-offs for four different age groups. a) Below 12 months b) 12-35 months c) 36-59 months and d) 60 months and above

the utility of this tool in our setting may be due to higher burden of background infectious disease. WHO recommended cut-off TLC values were largely driven by available data from the United States. It has been previously shown that normal values of $\mathrm{T}$ cell subset among African children may differ from those of other populations. A study in Guinea Bissau found healthy children under the age of 2 years to have lower CD4\% and CD4/CD8 ratios and higher CD8\% than their counterparts from developed countries [25].

Mahajan et al explored the utility of changes in TLC as a surrogate for changes in CD4 counts following HAART initiation among HIV-infected adults in India [26]. The main strength of this study was the multiple longitudinal TLC measurements with corresponding CD4 counts that allowed a comparison of changes as opposed to single value as is the case in our study. The study showed that an increase in TLC reliably predicts a corresponding rise in CD4 count but a falling TLC did not similarly predict a drop in CD4 count (98\% versus $63 \%$ positive and negative predictive values respectively. The study also noted substantial individual variation making it more difficult for a single TLC measurement to predict the actual quantitative CD4 change further highlighting the importance of multiple measurements [26].

The poor correlation between TLC and CD4\% in children in our study is of concern given that CD $4 \%$ is widely used in children to predict disease progression and is included in WHO guidelines for initiating HAART[14]. Moreover, CD4\% has been found to be an important prognostic marker even post HAART initiation in a large cohort of HIV Zambian infected children [27]. It is notable that in the Zambian study, low CD4\% was associated with mortality mainly among children < 18 months but not in those aged 18-59 months. 
Similarly in a cohort of HAART-treated HIV infected children in Kwazulu Natal, CD4\% was not predictor of mortality underscoring the fact that TLC may still be relevant despite lacking direct association with CD $4 \%$ [28].

An important group of HIV-infected children are those co-infected with tuberculosis as well as other conditions associated with leukocyte changes independent of HIV. Although no pediatric literature was found on this subject, among adults, Martin et al found strong correlation $(R=0.7)$ between TLC and CD4 count both at baseline and after 1 month of TB treatment in HIVTB co-infected South African adults [29]. In this study TLC of between $1300-1500 / \mathrm{ml}$ was highly predictive of CD4 count $<200 /$ ul.

In a broad context of expanding HIV treatment in settings with limited laboratory recourses, the DART trial, a randomized non-inferiority trial comparing clinically driven monitoring $(\mathrm{CDM})$ verses laboratory and clinical monitoring (LCM) found clinically 5 year survival rates of $87 \%$ verses $90 \%$ in CDM and LCM arms respectively [30]. While 12-weekly CD4 monitoring did not impact disease progression in the first 2 years of ART, after 2 years a small but significant increase in clinical disease progression was found in favour of the LCM. This clinical progression may be attributed to delay in switching to $2^{\text {nd }}$ line ART in the CDM with potential higher resistance. Thus whereas findings of the DART trial highlight the importance of CD4 testing in patients it remains crucial to similarly evaluate the role of TLC as surrogate for CD4 in HAART-treated children.

\section{Conclusions}

We conclude that in these Kenyan children TLC was positively correlated with absolute CD4 count, but current WHO age-specific TLC thresholds had low sensitivity to identify those who were severely immunosuppressed. Raising the TLC cut-off for all age groups considerably improved the sensitivity of TLC, retaining acceptable specificity and PPV, suggesting that at higher thresholds TLC has good utility as a tool to identify severely immune-depleted children requiring ART in settings where $\mathrm{CD} 4$ testing is not readily available. Limitations of our study include the modest sample size and fact that we only obtained single measurements of TLC and CD4. Our findings suggest that rather than shelve the use of TLC due to concerns of diagnostic utility, further research is needed to define optimum cut off values and should preferably be longitudinal with a much larger sample size. Considering the significantly higher cost of performing a CD4 count relative to TLC, and the limited availability of FACSCOUNT machines in Kenya, efforts that will lead to adoption of TLC will remove a major barrier to HAART initiation for HIV infected children, avert numerous deaths and help the country meet the targets of PEPfAR II.

\section{Acknowledgements}

The authors wish to acknowledge all the children and caregivers whose records were used in this study as well as the three institutions, Kenyatta National Hospital, Mbagathi District Hospital and Nyanza Provincial General Hospital for providing the data.

\section{Author details}

${ }^{1}$ Department of Pediatrics and Child Health, University of Nairobi, Nairobi, Kenya. ${ }^{2}$ Kenya Medical Research Institute-Wellcome Trust Research Program, Nairobi, Kenya.

\section{Authors' contributions}

NG participated in the design, data collection, and drafting of the manuscript. EMO conceived the study, and participated in its design and drafting of the manuscript. MN performed the statistical analysis. DW participated in statistical analysis and manuscript review. DMN participated in the drafting of the manuscript. All authors read and approved the final manuscript.

\section{Competing interests}

The authors declare that they have no competing interests.

Received: 30 December 2010 Accepted: 30 September 2011 Published: 30 September 2011

\section{References}

1. Kenya Demographic Health Survey: Central Bureau of Statistics, Nairobi; 2003, 89-91.

2. Kenya AIDS Indicator Survey: National AIDS Control Program Ministry of health Kenya; 2007.

3. Obimbo EM, Mbori-Ngacha DA, Ochieng JO, Richardson BA, Otieno PA, Bosire R, Farquhar C, Overbaugh J, John-Stewart GC: Predictors of Early Mortality in a Cohort of Human Immunodeficiency Virus Type-1 Infected African Children. Pediatr Infect Dis J 2004, 23(6):536-543.

4. Spira R, Lepage $P$, Msellati $P$, Van de Perre $P$, Leroy $V$, Simonon A, Karita E, Davis F: Natural history of human immunodeficiency virus type 1 infection in children: a five-year prospective study in Rwanda. Motherto-Child HIV-1 Transmission Study Group. Pediatrics 1999, 104(5):e56.

5. Tahaa TE, Kumwenda NI, Broadhead RL, Hoover DR, Graham SM, Van Der Hoven L, Markakis D, Liomba GN, Chiphangwi JD, Miotti PG: Mortality after the first year of life among Human Immunodeficiency Virus type 1infected and uninfected children. Pediatr Infect Dis J 1999, 18(8):689-94.

6. Mbori-Ngacha D, Nduati R, John G, Reilly M, Richardson B, Mwatha A, Ndinya-Achola J, Bwayo J, Kreiss J: Morbidity and mortality in breastfed and formula-fed infants of HIV-1-infected women: a randomized clinical trial. JAMA 2001, 286:2413-2420.

7. Wamalwa DC, Farquhar C, Obimbo EM, Selig S, Mbori-Ngacha DA, Richardson BA, Overbaugh J, Emery S, Wariua G, Gichuhi C, Bosire R, JohnStewart G: Early response to highly active antiretroviral therapy in HIV-1infected Kenyan children. J Acquir Immune Defic Syndr 2007, 45(3):311-7.

8. Nyandiko WM, Ayaya S, Nabakwe E, Tenge C, Sidle JE, Yiannoutsos CT, Musick B, Wools-Kaloustian K, Tierney WM: Outcomes of HIV-infected orphaned and non-orphaned children on antiretroviral therapy in western Kenya. J Acqir Immune Defic Syndr 2006, 43(4):418-25.

9. Reddi A, Leeper SC: Antiretroviral therapy adherence in children: outcomes from Africa. AIDS 2008, 22(7):906-7.

10. Van Winghem J, Telfer B, Reid T, Ouko J, Mutinga A, Jama Z, Vakil S: Implementation of a comprehensive program including psycho-social and treatment literacy activities to improve adherence to HIV care and treatment for a pediatric population in Kenya. BMC Pediatr 2008, 8:52.

11. Dunn D: Short-term risk of disease progression in HIV-1-infected children receiving no antiretroviral therapy or zidovudine monotherapy: a meta analysis. Lancet 2003, 362(9396):1605-11.

12. HIV Pediatric Prognostic Markers Collaborative Study: Predictive value of absolute CD4 cell count for disease progression in untreated HIV-1infected children. AIDS 2006, 20(9):1289-94. 
13. Dunn D, Woodburn P, Duong T, Peto J, Phillips A, Gibb D, Porter K, HIV Pediatric Prognostic Markers Collaborative Study (HPPMCS), Concerted Action on Sero-Conversion to AIDS and Death in Europe (CASCADE) Collaboration: Current CD4 cell count and the short-term risk of AIDS and death before the availability of effective antiretroviral therapy in HIV-infected children and adults. J Infect Dis 2008, 197(3):398-404.

14. World Health Organization: Antiretroviral therapy of HIV infection in infants and children in resource-limited settings: towards universal access. Recommendations for a public health approach 2006.

15. Beck EJ, Kupek EJ, Gompels MM, Pinching AJ: Correlation between total and CD4 lymphocyte counts in HIV infection: not making the good an enemy of the not so perfect. Int J STD AIDS 1996, 6:422-8.

16. Spacek LA, Griswold M, Quinn TC, Moore RD: TLC and hemoglobin combined in an algorithm to initiate the use of HAART in resource limited settings. J AIDS 2003, 17:1311-1317.

17. Kumarasamy N, Mahajan AP, Flamigan TP, Hemalatha R, Mayer KH, Carpenter CC, Thyagarajan SP, Solomon S: TLC is a useful tool for the timing of opportunistic infection prophylaxis in India and other resource constrained settings. J Acquir Immune Defic Sndr 2002, 31:378-83.

18. Gitura BM, Joshi MD, Lule GN, Anzala O: Total Lymphocyte Count as a surrogate marker for CD4+ T cells count in initiating HAART at Kenyatta National Hospital, Nairobi. East African Medical Journ 2007, 84:466-472.

19. Kamya MR, Semitala FC: TLC of 1200 is not a sensitive predictor of CD4 Lymphocyte count among patients with HIV disease in Kampala, Uganda. Afr Health Science 2004, 2:941-101.

20. Spitalnic S: Test properties 1: Sensitivity, Specificity and predictive values Hospital Physician. 2004, 1:27-31 [http://www.turner-white.com]

21. Dunn DT, Gibb DM, Duong T, Babiker AG, et al: Use of TLC for informing when to start ART in HIV infected children. Lancet 2005, 366:1868-74.

22. The President's Emergency Plan For AIDS Relief, (PEPFAR), Next Generation Indicators Reference Guide. [http://www.pepfar.gov].

23. Flanigan TP, Mahajan AP, Kumarasamy N: TLC as a surrogate for CD4 count to initiate and monitor HAART in resource limited countries. 9th Conference on Retroviruses and Opportunistic Infections. Seattle, February 2002

24. Musoke PM, Young AM, Owor M, Lubega IR, Brown ER, Mmiro FA Mofenson LM, Jackson JB, Fowler MG, Guay LA: Total Lymphocyte Count: Not a surrogate marker for risk of death in HIV infected Ugandan children. J Acquir Immune Defic Syndr 2008, 49:171-178.

25. Kiepiela P, Coovadia HM, Coward P, Woodhead R, Abdool-Karim SS, Becker P: Age-related lymphocyte sub-population changes among health African from birth to adulthood. Ann Trop Pedtr 1989, 9:199-205.

26. Mahajan AP, Hogan JW, Snyder B, Kumarasamy N, Mehta K, Solomon S, Carpenter CC, Mayer KH, Flanigan TP: Changes in total lymphocyte count as a surrogate for changes in CD4 count following initiation of HAART: implications for monitoring in resource-limited settings. J Acquir Immune Defic Syndr 2004, 36(1):567-75.

27. Bolton-Moore C, Mubiana-Mbewe M, Cantrell J, Chintu N, Stringer EM, Chi BH, Sinkala M, Kankasa C, Wilson CM, Wilfert CM, Mwango A, Levy J, Abrams EJ, Bulterys M, Stringer JS: Clinical outcomes and CD4 response in children receiving antiretroviral therapy at primary health care facilities in Zambia. JAMA 2007, 298(16):1888-1899.

28. Reddi A, Leeper SC, Grobler AC, Geddes R, France KH, Dorse GL, Viok WJ, Mntambo M, Thomas M, Nixon K, Holst HL, Karim QA, Rollins NC, Coovadia HM, Giddy J: Preliminary outcomes of a paediatric highly active antiretroviral therapy cohort from KwaZulu-Natal, South Africa. BMC Pediatr 2007, 7:7-13.

29. Martin DJ, Sim JG, Sole GJ, Rymer L, Shalekoff S, van Niekerk AB, Becker P, Weilbach CN, Iwanik J, Keddy K, et al: CD4+ lymphocyte count in African patients co-infected with HIV and tuberculosis. J Acquir Immune Defic Syndr Hum Retrovirol 1995, 8(4):386-91.

30. DART Trial team: Routine versus clinically driven laboratory monitoring of HIV antiretroviral therapy in Africa (DART): a randomized non-inferiority trial. Lancet 2010, 375:123-31.

Pre-publication history

The pre-publication history for this paper can be accessed here:

http://www.biomedcentral.com/1471-2334/11/259/prepub doi:10.1186/1471-2334-11-259

Cite this article as: Githinji et al: Utility of total lymphocyte count as a surrogate marker for CD4 counts in HIV-1 infected children in Kenya. BMC Infectious Diseases 2011 11:259.

\section{Submit your next manuscript to BioMed Central and take full advantage of:}

- Convenient online submission

- Thorough peer review

- No space constraints or color figure charges

- Immediate publication on acceptance

- Inclusion in PubMed, CAS, Scopus and Google Scholar

- Research which is freely available for redistribution 